\title{
Aromatic Constituents of Stachys sp. aff. schimperi
}

\author{
Mamdoun Abdel-Mogib and Hassan S.M. Al-Zahrani \\ Department of Chemistry; and Department of Biology, \\ Faculty of Science, King Abdulaziz University, Jeddah, Saudi Arabia
}

\begin{abstract}
AвSTRACт. Stachys sp. aff. schimperi (family Labiatae) is a widespread species in the south west of the Kingdom of Saudi Arabia. This plant species has not been investigated previously for its chemical constituents. Chromatographic separation of its extract afforded $\beta$-sitosterol and stigmasterol. Additionally, some fatty acids, 2-hydroxy-4-phenylbutanoic acid, syringic acid, vanillic acid, isoferulic acid and $p$-coumaric acid were identified by GC/MS technique. In addition to two flavonoids; 4',5-dihydroxy-6,7,8-trimethoxyflavone and 4',5-dihydroxy3,6,7,8-tetramethoxyflavone, were identified by the proton NMR and the MS spectra.
\end{abstract}

\section{Introduction}

The genus Stachys of the family Labiatae comprises many medicinal plants. $S$. baicalensis is prescribed in the USSR for the treatment of hypertension, $S$. lavandulifolia is used in Jordan for indigestion and $S$. officinalis is used in Ukrainea for treating heart disorders. Also, in Ukrainea compresses made with $S$. recta boiled in milk are applied for rheumatism ${ }^{[1]}$.

Typical phytochemical constituents of the genus Stachys are essential oils ${ }^{[2-5]}$, $\mathrm{C}_{9}$-iridoidal glycosides ${ }^{[6,7]}$, labdane $^{[8,9]}$ and neo-clerodane ${ }^{[9,10]}$ diterpenoids, flavonoids $^{[11-13]}$, megastagmane glycosides ${ }^{[14]}$, phenylpropanoids ${ }^{[7,15,16]}$, and phenylethanoids ${ }^{[17]}$.

Stachys sp. aff. schimperi is an aromatic species, commonly distributed in the south west of Saudi Arabia, was not investigated previously for chemical constituents. In this article, we report the isolation of many aromatic constituents from this species. 


\section{Experimental}

\section{General}

GC/MS spectra were taken on a QP-7000 Shimadzu, with fused silica capillary column (30 m $\times 0.25 \mathrm{~mm}$ ID), film (5\% phenyl, 95\% methylsilicon) thickness $0.25 \mu$, and the output of an IBM computer with software Class 500 and NIST library for comparison; NMR spectra were recorded on Bruker FT-400 MHz.

\section{Plant Material}

Stachys sp. aff. schimperi was collected in January 2001 from Taief-Baha road at Mayssan about $100 \mathrm{~km}$ south of Taif, Saudi Arabia and identified by Prof. Dr. A. Faied, Botany Dept., Faculty of Science, King Abdulaziz University. A specimen was deposited in the Herbarium of Botany Dept., Faculty of Science, King Abdulaziz University.

\section{Processing of Plant Material}

The air-dried, whole plant, $(680 \mathrm{~g})$ was cut into small pieces and extracted at room temperature by soaking in a mixture of methanol/ether/pet. ether $40-60^{\circ}$ (1:1:1) for 24 hours. The crude extract $(31.7 \mathrm{~g})$ was defatted by dissolving in cold $\mathrm{MeOH}(150 \mathrm{ml})$ and standing in the fridge freezer for overnight, then, quick filtration and evaporation gave the defatted extract (20.8 g).

\section{Separation of Compounds}

The defatted extract was fractionated over silica gel $(160 \mathrm{~g})$ CC $(100 \mathrm{~cm}$ length $\times 4 \mathrm{~cm}$ inner diameter) using stepwise elution into three main fractions.

The second fraction (Ss2, $6.2 \mathrm{~g}$, eluted by pet.ether/ether 1:1) was rich in chemical constituents. It was reseparated on sephadex LH-20 CC into 13 fractions (Ss21-Ss29, Ss210, Ss211, Ss212, Ss213). Fraction Ss24 (540 mg, eluted by pet. ether/ $\mathrm{CH}_{2} \mathrm{Cl}_{2}$ 1:4) afforded a mixture of $\beta$-sitosterol, stigmasterol, flavonoid 6 and flavonoid 7 (4:1:3:4). Fraction Ss26 (93 mg, eluted by pet. ether/ $\mathrm{CH}_{2} \mathrm{Cl}_{2}$ 1:4) contained flavonoid 7 .

Fraction Ss210 (1.2 g, eluted by $\mathrm{CH}_{2} \mathrm{Cl}_{2} /$ acetone $\left.4: 1\right)$ gave by GC/MS the hydroxyacid 1 (at $\mathrm{R}_{\mathrm{t}} 8.00$ min., 37.5\%), syringic acid 2 (at $\mathrm{R}_{\mathrm{t}} 10.12 \mathrm{~min}$., 6.3\%), palmitic acid (at $\mathrm{R}_{\mathrm{t}} 11.58$ min., $15.6 \%$ ), linoleic acid (at $\mathrm{R}_{\mathrm{t}} 13.27$ min., $6.2 \%$ ), and oleic acid (at $R_{t} 13.33$ min., 7.5\%).

Fraction $\mathrm{Ss} 211$ (820 mg, eluted by $\mathrm{CH}_{2} \mathrm{Cl}_{2}$ /acetone 3:2) afforded by GC/MS vanillic acid 3 (at $R_{t} 7.30$ min., $11.7 \%$ ), the hydroxyacid 1 (at $R_{t} 8.00$ min., $5.0 \%$ ), nonandioic acid (at $R_{t} 8.23$ min., 18.3\%), isoferulic acid 4 (at $R_{t} 9.46$ 
min., 3.3\%), syringic acid 2 (at $\mathrm{R}_{\mathrm{t}} 10.12 \mathrm{~min}$., 7.3\%), palmitic acid (at $\mathrm{R}_{\mathrm{t}} 11.58$ min., 16.7\%), oleic acid (at $R_{t} 13.35$ min., 13.3\%) and stearic acid (at $R_{t} 13.58$ $\min ., 4.7 \%)$.

Fraction Ss212 (750 mg, eluted by acetone) gave by GC/MS vanillic acid 3 (at $\mathrm{R}_{\mathrm{t}} 7.32$ min., 7.4\%), nonandioic acid (at $\mathrm{R}_{\mathrm{t}} 8.23 \mathrm{~min} ., 29.6 \%$ ), palmitic acid (at $\mathrm{R}_{\mathrm{t}} 11.57$ min., 11.1\%), linoleic acid (at $\mathrm{R}_{\mathrm{t}} 13.28 \mathrm{~min}$., 30.4\%) and stearic acid (at $\mathrm{R}_{\mathrm{t}} 13.59$ min., 3.0\%).

Fraction Ss213 (660 mg, eluted by acetone) afforded by GC/MS $p$-coumaric acid 5 (at $\mathrm{R}_{\mathrm{t}} 9.86$ min., 9.1\%), palmitic acid (at $\mathrm{R}_{\mathrm{t}} 11.57$ min., 18.3\%), linoleic acid (at $\mathrm{R}_{\mathrm{t}} 13.28 \mathrm{~min} ., 13.6 \%$ ), oleic acid (at $\mathrm{R}_{\mathrm{t}} 13.35 \mathrm{~min} ., 20.0 \%$ ) and stearic acid (at $\mathrm{R}_{\mathrm{t}} 13.58$ min., 6.4\%).

\section{Results and Discussion}

The extract of Stachys sp. aff. schimperi was separated firstly by silica gel CC. The main fraction was reseparated on sephadex LH-20, followed by GC/ MS, in case of some fractions, to give two phytosterols, two flavonoids, five fatty acids and five aromatic acids.

The separated compounds were identified from their ${ }^{1} \mathrm{H}$ NMR and MS spectra and were confirmed by comparing with authentic spectra or literature data.

The phytosterols were $\beta$-sitosterol ${ }^{[18]}$ and stigmasterol ${ }^{[18]}$. The fatty acids were palmitic ${ }^{[18]}$, linoleic ${ }^{[18]}$, oleic ${ }^{[18]}$, stearic ${ }^{[18]}$ and azelaic (nonandioic) ${ }^{[19]}$. The aromatic acids were 2-hydroxy-4-phenylbutanoic acid $\mathbf{1}^{[20]}$, syringic acid $\mathbf{2}^{[21]}$, vanillic acid $\mathbf{3}^{[21]}$, isoferulic acid $\mathbf{4}^{[21]}$ and $p$-coumaric acid $\mathbf{5}^{[22]}$.

A spot of flavone 6 on a chromatographic plate was yellow in colour, brown under the UV light and turned flourescent blue when fumed by ammonia and viewed under UV. Structure of flavone 6 was followed from ${ }^{1} \mathrm{H}$ NMR spectrum (in $\mathrm{CDCl}_{3}$ ), which gave a singlet in the downfield at $\delta 12.5 \mathrm{ppm}(\mathrm{C}-5 \mathrm{OH})$, an AA'BB' system at $\delta 6.97$ and 7.82 with coupling of $8.6 \mathrm{~Hz}$ due to ring B (4'oxygenated), in addition to three methoxyl group singlets at $\delta 4.12,3.98,3.96$ ppm and a $1 \mathrm{H}$-singlet at $\delta 6.60$, which was in agreement with H-3. Thus 6 was found by comparison with authentic spectra to be 4',5-dihydroxy-6,7,8-trimethoxyflavone, isolated previously from $S$. aegyptiaca ${ }^{[12]}$. The structure was supported also by the MS spectrum.

A spot of flavone 7 on a chromatographic plate was yellow in colour, brown under the UV light and turned flourescent blue when fumed by ammonia and viewed under UV. ${ }^{1} \mathrm{H}$ NMR spectrum of 7 (in $\mathrm{CDCl}_{3}$ ) was approximately similar to that of $\mathbf{6}$. But the singlet of H-3 disappeared, the methoxyl group singlets became four (at $\delta 4.11,3.96,3.95,3.86$ ) and the downfield component of 
the AA'BB' system moved from 7.82 to $8.10 \mathrm{ppm}$, in agreement with additional $\mathrm{C}-3 \mathrm{OCH}_{3}$ group. Thus 7 was identified as 4',5-dihydroxy-3,6,7,8-tetramethoxyflavone, which was isolated previously from $S$. aegyptiaca ${ }^{[23]}$. The structure was supported also by the MS spectrum.<smiles>O=C(O)C(O)CCc1ccccc1</smiles>

1<smiles>[R]c1ccc(/C=C/C(=O)O)cc1[R]</smiles>

4; $\mathrm{R}^{1}=\mathrm{OCH}_{3}, \mathrm{R}^{2}=\mathrm{OH}$ 5; $\mathrm{R}^{1}=\mathrm{OH}, \mathrm{R}^{2}=\mathrm{H}$<smiles>[R]c1cc(C(=O)O)cc(OC)c1O</smiles>

2; $\mathrm{R}=\mathrm{OCH}_{3}$

$\mathrm{OH}$ 3; $\mathrm{R}=\mathrm{H}$<smiles>[R]c1c(-c2ccc(O)cc2)oc2c(OC)c(OC)c(OC)c(O)c2c1=O</smiles>

6; $\mathrm{R}=\mathrm{H}$

7; $\mathrm{R}=\mathrm{OCH}_{3}$

\section{References}

[1] Rivera Nunez, D. and Obon de Castro, C., The Ethnobotany of the Old World Labiatae. In: R.M. Harley and T. Reynolds (Editors)., Advances in Labiatae Science, p. 455, Royal Botanic Gardens, Kew (1992).

[2] Chalchat, J.C., Petrovic, S.D., Maksimovic, Z.A. and Gorunovic, M.S., J. Essent. Oil Res. 13: 286 (2001).

[3] Chalchat, J.C., Petrovic, S.D., Maksimovic, Z.A. and Gorunovic, M.S., J. Essent. Oil Res., 12: 455 (2000).

[4] Skaltsa, H.D., Lazari, M.D., Chinou, I.B. and Loukis, A.E., Planta Med. 65: 255 (1999).

[5] Duru, M.E., Cakir, A., Harmandar, M., Izumi, S. and Hirata, T., Flavour Frag. J. 14: 12 (1999).

[6] Muñoz, O., Peña, R.C. and Montenegro, G., Z. Naturforsch. C, 56: 902 (2001).

[7] Calis, I., Basaran, A.A., Saracoglu, I. and Sticher, O., Phytochemistry, 31: 167 (1992).

[8] Paternostro, M.P., Maggio, A.M., Piozzi, F. and Servettaz, O., J. Nat. Prod. 63: 1166 (2000).

[9] Fazio, C., Paternostro, M.P., Passannanti, S. and Piozzi, F., Phytochemistry, 37: 501 (1994).

[10] Fazio, C., Passannanti, S., Paternostro, M.P. and Piozzi, F., Phytochemistry, 31: 3147 (1992). 
[11] El-Ansari, M.A., Nawwar, M.A. and Saleh, N.A.M., Phytochemistry, 40: 1543 (1995).

[12] Sharaf, M., Fitoterapia, 69: 355 (1998).

[13] Tomasbarberan, F.A., Gil, M.L., Ferreres, F. and Tomaslorente, F., Phytochemistry, 31: 3097 (1992).

[14] Takeda, Y., Zhang, H.J., Masuda, T., Honda, G., Otsuka, H., Sezik, E., Yesilada, E. and Sun, H.D., Phytochemistry, 44: 1335 (1997).

[15] Miyase, T., Yamamoto, R. and Ueno, A., Phytochemistry, 43: 475 (1996).

[16] Basaran, A.A., Calis, I., Anklin, C., Nishibe, S. and Sticher, O., Helv. Chem. Acta, 71: 1483 (1988).

[17] Nishimura, H., Sasaki, H., Inagaki, N., Chin, M. and Mitsuhashi, H., Phytochemistry, 30: 965 (1991).

[18] Abdel-Mogib, M., Phytochemistry, 51: 445 (1999).

[19] Runa, H., Zhang, Y., Wu, J., Deng, S., Sun, H. and Fujita, T., Fitoterapia, 73: 288 (2002).

[20] Chadha, A. and Manohar, M., Tetrahedron Asym., 6: 651 (1995).

[21] Dawidar, A.M., Ezmirly, S.T., Abdel-Mogib, M., El-Dessouki, Y. and Angawi, R.F., Pharmazie, 55: 848 (2000).

[22] Poyrazoglu, E., Goekmen, V. and Artik, N., J. Food Comp. Anal., 15: 567 (2002).

[23] El-Ansari, M.A., Barron, D., Abdalla, M.F., Saleh, N.A.M. and Lequere, J.L., Phytochemistry, 30: 1169 (1991). 


\title{
المكونات العطرية لنوع استاكس شبيه شمبري
}

\author{
ممدوح عبد المجيب* و حسن سعيد مبارك الزهراني \\ *قسم الكيمياء - *ققسم علوم الأحياء ، كلية العلوم ، جامعة الملك عبد عبد العزيز

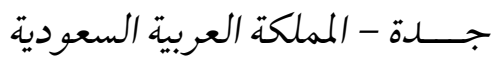

المستخلص. يتشر نوع استاكس شبيه شمبري (الفصيلة الشفوية)

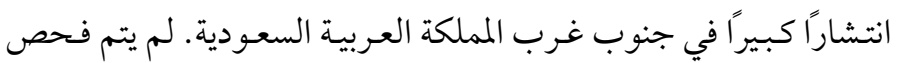

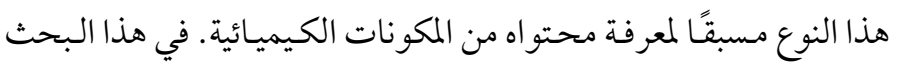

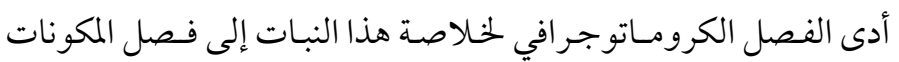

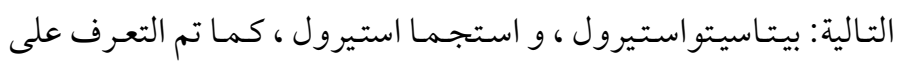

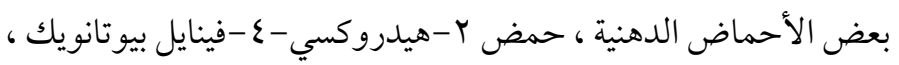

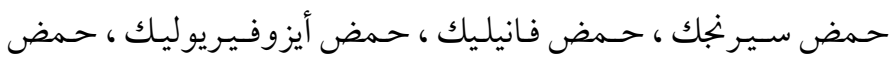

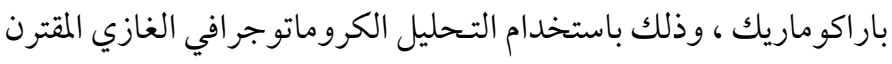

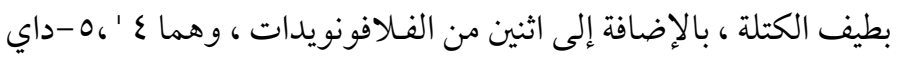

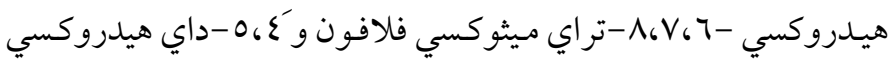

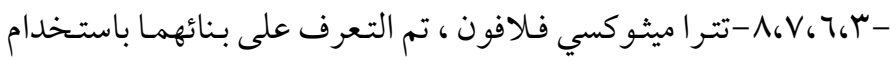
طيف الرنين النووي للبروتون بالإضافة إلى طيف الكتلة. 